IRA-International Journal of Technology \& Engineering ISSN 2455-4480

Proceedings of the

International Conference on Science \&

Engineering for Sustainable Development (2017)

Pg. no.181-192

Published by: Institute of Research Advances

https://research-advances.org/index.php/IRAJTE

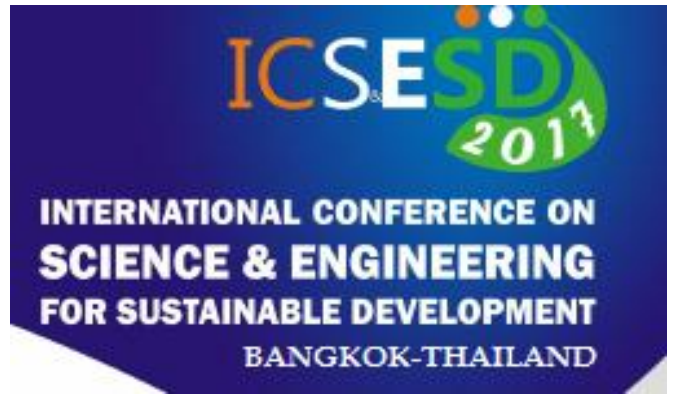

\title{
Design and Optimization of a Shearing Machine Using FEA
}

\author{
Satish G. Bahaley ${ }^{* 1}$, Rasika S. Khairkar ${ }^{2}$ \\ ${ }^{1}$ Professor, Mechanical Engineering Department, PRMIT \& R, Badnera, Amravati, India. \\ ${ }^{2}$ PG Student, Mechanical Engineering Department, PRMIT\& R, Badnera, Amravati, \\ India.
}

Type of Review: Originality Check \& Peer Review under the responsibility of the Scientific Committee of the Conference and The Institution of Engineers (India). DOI: http://dx.doi.org/10.21013/jte.ICSESD201718

\section{How to cite this paper:}

Bahaley, S., Khairkar, R. (2017). Design and Optimization of a Shearing Machine Using FEA. Proceedings of the International Conference on Science \& Engineering for Sustainable Development (2017), 181-192. doi: http://dx.doi.org/10.21013/jte.ICSESD201718

(C) International Conference on Science \& Engineering for Sustainable Development\& The Institution of Engineers (India).

\section{$(\mathrm{cc}) \overline{\mathrm{BY}-\mathrm{NC}}$}

This work is licensed under a Creative Commons Attribution-Non Commercial 4.0 International License subject to proper citation to the publication source of the work.

Disclaimer: The conference papers as published by the Institute of Research Advances (IRA) are the views and opinions of their respective authors and are not the views or opinions of the IRA. The IRA disclaims of any harm or loss caused due to the published content to any party. 


\section{ABSTRACT}

Shearing is the process to cut sheets using pair of blades, by applying shear stress along the thickness of the sheet. Shearing happens by extreme plastic deformation followed by breaking which propagates deeper into the thickness. The upper blade is fixed to the ram assembly that moves vertically and lower knife is fixed in the stationary table. This project is rooted on the necessity of industry to develop a shearing machine for cutting $5 \mathrm{~mm}$ thick stainless steel sheets. In this project we will design a CAD model of shearing machine and analyze using FEA technique.

Keywords: CAD Model, FEA, Shearing Machine, Shear Stress, Stainless Steel Sheet

\section{Introduction}

- The Shearing process involves cutting sheet metal into individual pieces by subjecting it to shear stresses in the thickness direction, typically using a punch and die, similar to the action of a paper punch[1].

- Shearing type operations include: blanking, piercing, roll slitting, and trimming[4].

- Unlike cup drawing where the clearance between the punch and the die is about $10 \%$ larger than the sheet thickness, the clearance in conventional shearing is form 4 to $8 \%$ of the sheet thickness. Usually the clearance between the punch and die is $5 \%$ to $40 \%$ of the thickness of sheet metal[5].

- There are many types of sheet metal cutting processes, defined by the relationship of the tool position angle and the thickness of the sheet to be cut. Alligator shear, Bench shear, Guillotine, Power Shear and Throatless shear these are the most common type of cutting process[1][2][3].

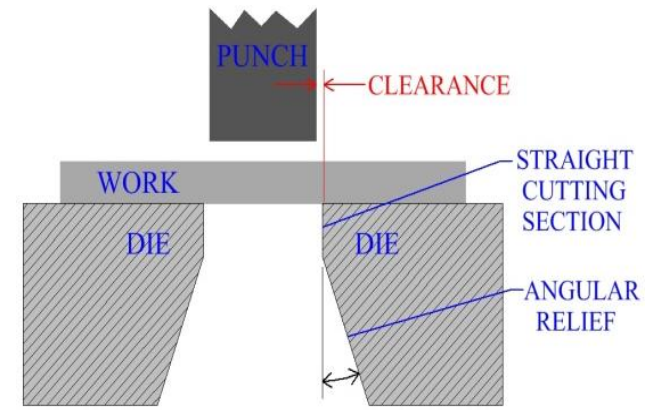

Figure 1.Simple Diagram of Shearing Machine[1]

\section{Objectives}

- To design a shearing machine for cutting $5 \mathrm{~mm}$ thick stainless steel sheets.

- To perform hand calculations to arrive at the given machine design and configuration.

- To optimize the structure of designed machine using FEA.

- To design a plate shearing machine which is less costly.

\section{Literature Review}

The Shearing Machine meant for cutting 37/19 pins spent fuel bundles into 11 pieces employing multi blade assembly shall be designed \& manufactured in line with that of existing 19 pins Shearing Machines, improvements made on the existing 19 pins machines and other details such as design basis, layout (civil $\&$ machine) etc provided in this document. Details of simulated $37 \& 19$ pins simulated dummy bundles are provided under Para-4.4mm.The machine mainly comprises of Mechanical System, Hydraulic System 
and Electrical \& Control System. The mechanical system performs the operations of fuel pushing, placing the fuel bundle between shear blades, chopping \& diverting the cut pieces to either dissolver limb-1 or 2 with one of the side distributor door in open condition. The hydraulic system facilitates pushing \& chopping of fuel bundles employing a common power pack whereas electrical \& control system provides electrical power to various actuators and controls the operation of SFC through PLC which receives the signal from field sensors[3].

Special Purpose Machines (SPM) are widely used in modern era of manufacturing. SPM are designed in such a way that they can easily perform the desired operations. SPM minimizes the operation time, human fatigue due to repetitive operation, product cost; it increases the productivity and assures the quality. The recent advancement in digital systems have now enabled us to make low cost machines.Sheet metal cutting is automatic machines like circle cutting New Changes and Cut according to marking with the help of Chisel and Hammer the primary process of all the processes. The sheet metal cutting is needed in manufacturing different shapes of parts of the thresher machine. 15- 20 parts of each thresher are from sheet metal. Proper cutting provide the proper folding and close fits into the mating parts. Sheet metal cutting is so equally important like any other operation otherwise the parts cannot be in required dimensions. The shape and geometry of the each part body is very different than any other component. The manual cutting by chisel- hammer and manual shear machine is the only option on which the sheet metal cutting operation can perform. There are so many aspects involved in the actual operation, but currently there is no other option other than manual cutting[1].

\section{Need of Designing The Shearing Machine}

- During a visit to the DAULAT INDSUTRIES, it was revealed that there is a requirement for shearing machine to cut $5 \mathrm{~mm}$ thick sheets of stainless steel (ss).

- There are various shearing machine available in the market to perform this task. But the general manager at Daulat Industries is insisting to design and fabricate the machine in house.

- After a detailed conversation with the general manger it was decided that the designing and optimizing part of the shearing machine would be executed in this project.

- In this project, the design and optimization of a shearing machine which is capable of cutting $5 \mathrm{~mm}$ thick stainless steel sheets will be designed and optimized with the help of CAD and FEA software's.

- With this project the company will be benefited from the advancements of computer technologies and thus will be able to reduce cost of procuring a shearing machine.

\section{A. Problems:}

- Existing process require high labor cost.

- Existing process require high process time.

- Many accidents encountered with existing process.

B. Requirements:

- Process should decrease the labor cost.

- It should cut minimum 5mm thick plate.

- To increase workers safety.

- Process should increase the productivity. 


\section{CALCULATIONS}

Design of shearing machine to cut $5 \mathrm{~mm}$ thick and $2.4 \mathrm{~m}$ length of cut.

$$
\begin{gathered}
\text { ShearForce }=\text { ShearStress } \times \text { Area } \\
\text { Syt }=0.7 \times \text { UltimateStress } \\
\text { Syt }=0.7 \times 510 \\
\text { Syt }=357 \mathrm{MPa} \\
\text { ShearStrength }=\frac{357}{2}=178.5>150 \mathrm{MPa} \quad \text { (For 5.8 Carbon Steel) } \\
\text { ShearForce }=150 \times 5 \times 2438.4 \\
\text { ShearForce }=1828800 \mathrm{~N} \\
=\frac{\text { ShearForce }}{9.81}=\frac{1828800}{9.81}=186 \text { Ton }
\end{gathered}
$$

2 hydraulics of 100 Ton each will be used to provide 186 Ton.

CASE 1: Load of 200 Ton is upward direction acting horizontal members at bolt locations.

$$
200000 \times 9.81=1962 \mathrm{kN}
$$

There are 10 horizontal members sharing this load and 4 locations at each member,

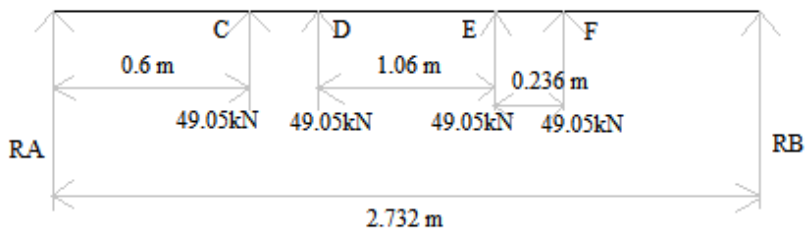

Figure 2. Channel As a Beam

$$
\begin{gathered}
\frac{1962}{10 \times 4}=49.05 k N \\
R A+R B=-196.2 k N \\
R A=R B=98.1 k N \\
B M X=-(98.1 \times 1.366)+(49.05 \times 0.766)+(49.05 \times 0.53) \\
B M X=-70.436 \mathrm{kNm}=70436000 \mathrm{Nmm} \\
I=\frac{1}{12} \times\left\{\left(120 \times 120^{3}\right)-\left(70 \times 20^{3}\right)\right\}
\end{gathered}
$$




$$
I=17233333.33 \mathrm{~mm}^{4}
$$

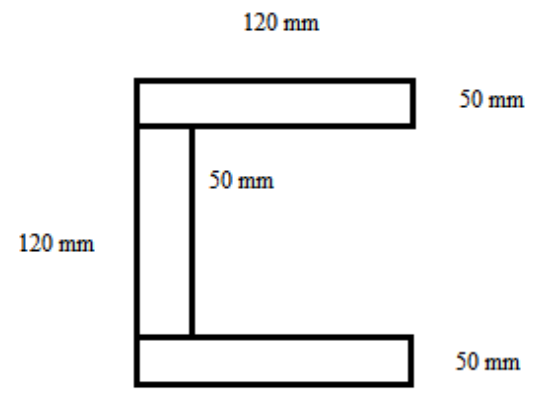

Figure 3. Cross Section of Channel

$$
\begin{gathered}
\sigma=\frac{M}{I} \times y \\
\sigma=\frac{70436000}{17233333.33} \times 60 \\
\sigma=245.23 \mathrm{MPa}
\end{gathered}
$$

CASE 2: Plate in contact with tool throughout the length, 4 support

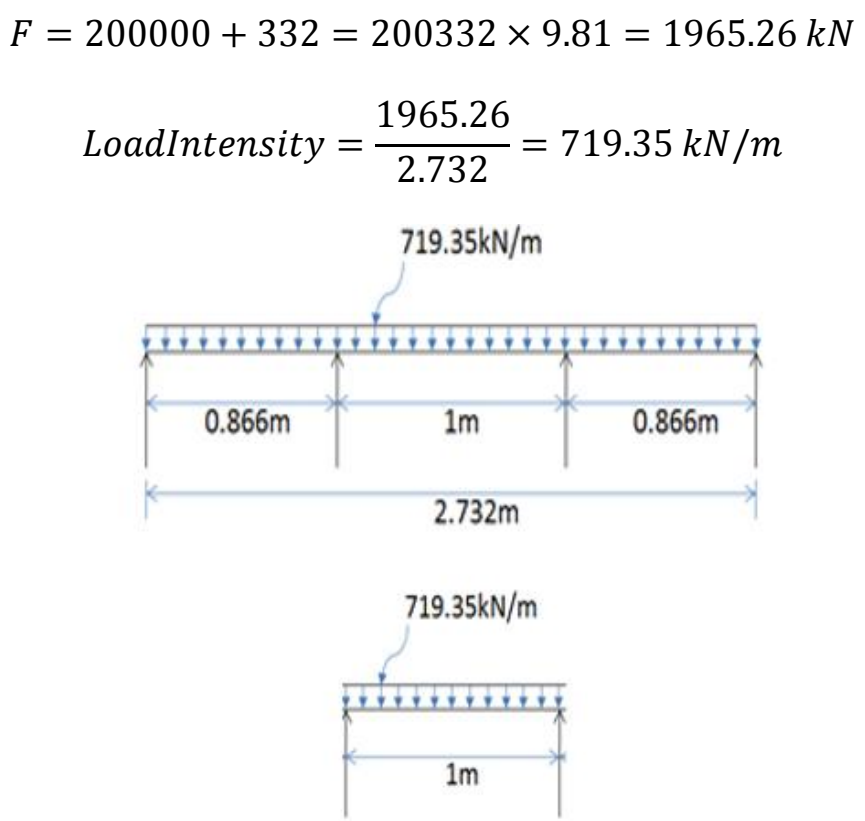

Figure 4. Loading Diagram (Simple Beam:-Uniformly Distributed Load)

Considering only center portion,

$$
\begin{aligned}
& R A+R B=719.35 k N \\
& R A=R B=359.67 k N
\end{aligned}
$$




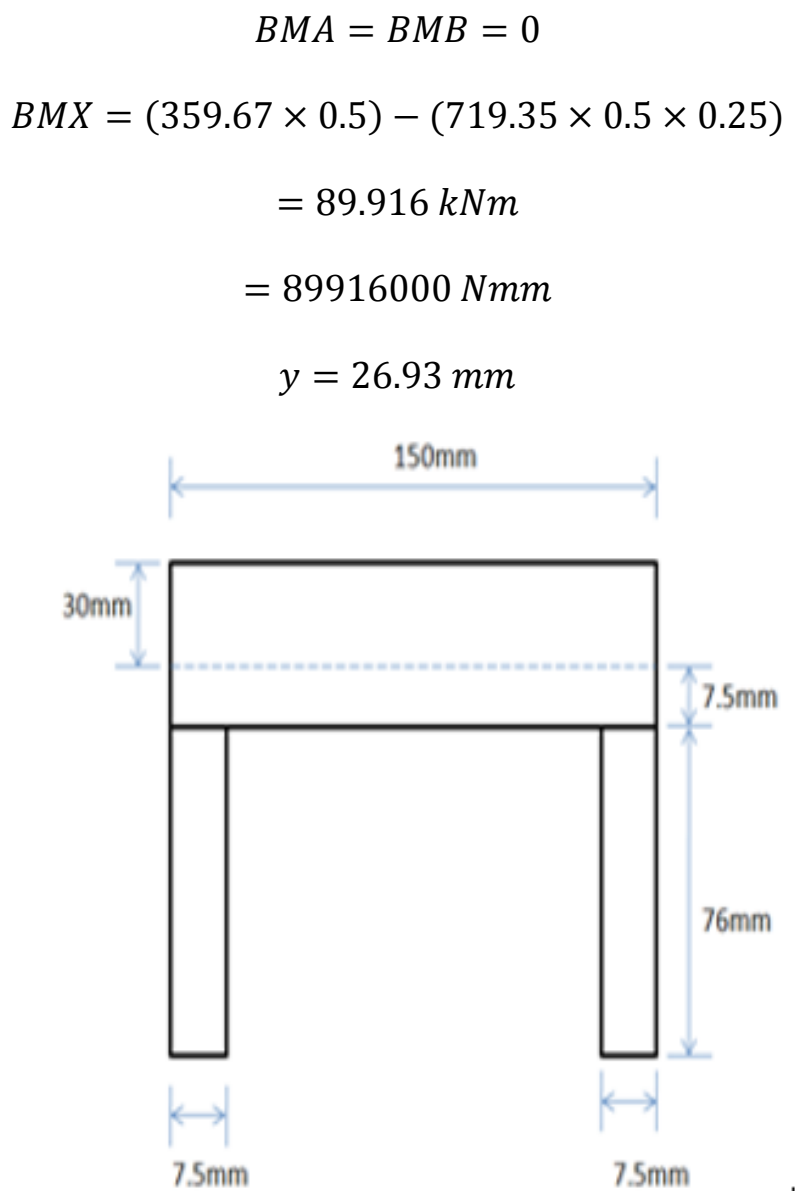

Figure 5. Cross Section of Tool Assembly

$$
\begin{gathered}
I=\frac{1}{12} \times\left\{\left(150 \times 113.5^{3}\right)-\left(135 \times 68.5^{3}\right)\right\} \\
I=14660727.03 \mathrm{~mm}^{4} \\
\sigma=\frac{M}{I} \times y \\
\sigma=\frac{89916000}{14660727.03} \times 26.93 \\
\sigma=165.16 \mathrm{MPa}
\end{gathered}
$$

CASE 3: Buckling of Vertical Member

$$
\begin{aligned}
& \text { DownwardForce }(\text { weight })=5.79 k N \\
& \text { UpwardForce }(200 \text { Ton })=1962 k N \\
& 1962-5.79=1956.21 k N(\text { upward })
\end{aligned}
$$


This load is shared by 12 members,

$$
\begin{gathered}
\frac{1956.21}{12}=163.017 k N \\
P c r=\frac{\pi^{2} E I}{L e^{2}}
\end{gathered}
$$

Column end condition: Both end fixed,

$$
\begin{gathered}
L e=0.5 L=0.5 \times 1750=875 \mathrm{~mm} \\
E=210000 \mathrm{MPa}
\end{gathered}
$$
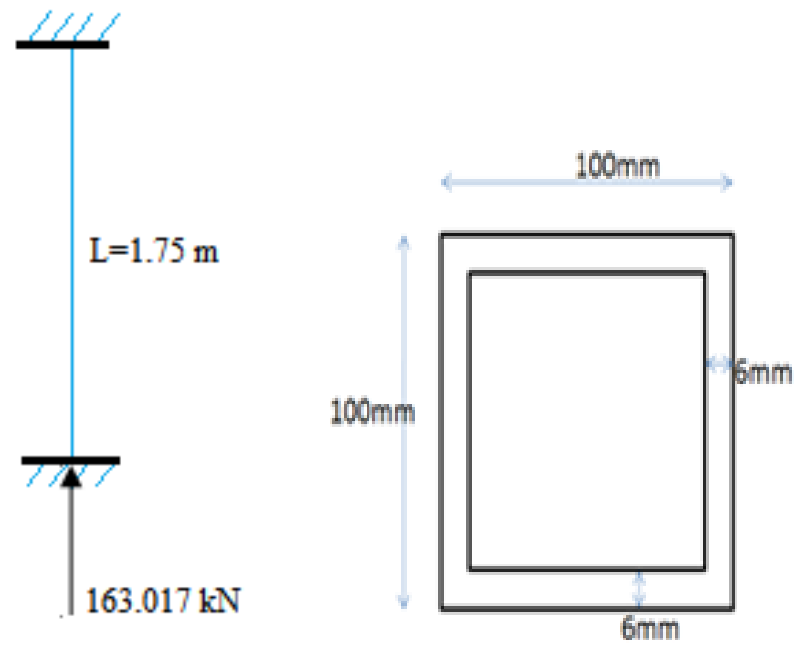

Figure 6. Cross Section of Hollow Square Tube

$$
\begin{gathered}
I=\frac{1}{12} \times\left\{100^{4}-88^{4}\right\} \\
I=3335872 \mathrm{~mm}^{4} \\
P c r=\frac{\pi^{2} \times 210000 \times 3335872}{875^{2}} \\
P c r=9030.5 \mathrm{kN}
\end{gathered}
$$$$
\text { Pcr }>\text { P }=\text { Stable Structure }
$$

Compressive Stress:

$$
\begin{gathered}
\sigma=\frac{F}{A} \\
\sigma=\frac{163017}{2256}
\end{gathered}
$$




$$
\sigma=72.26 \mathrm{MPa}
$$

\section{Cad Modelling Of Shearing Machine}

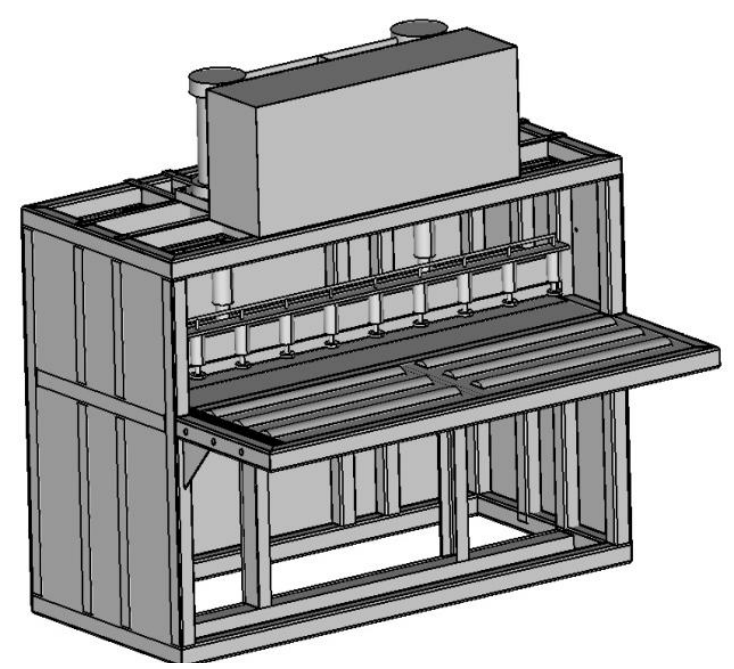

Image 1. CAD Model of Shearing Machine

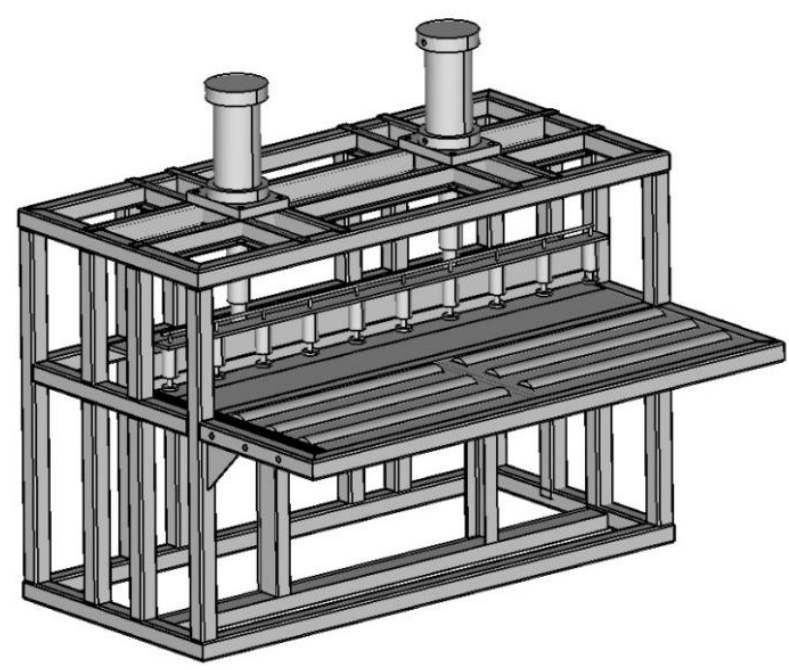

Image 2. Isometric View of Shearing Machine 


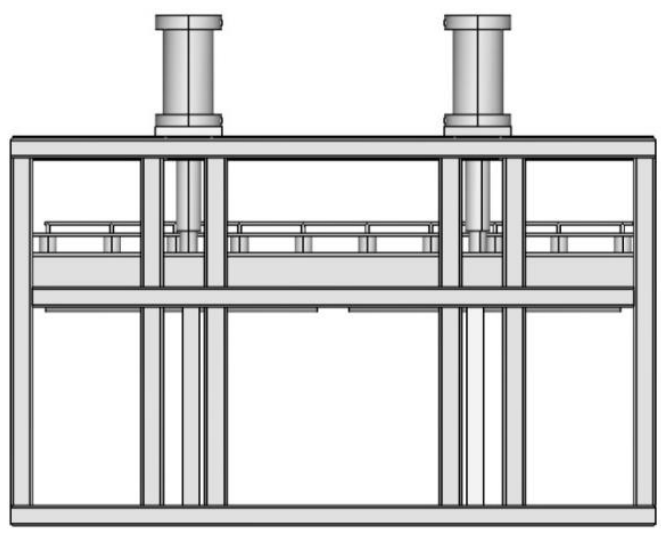

Image 3. Front View of Shearing Machine

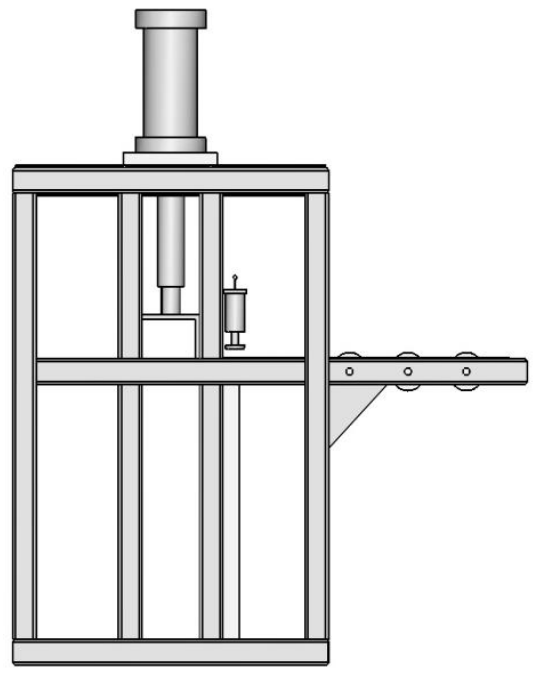

Image 4. Side View of Shearing Machine

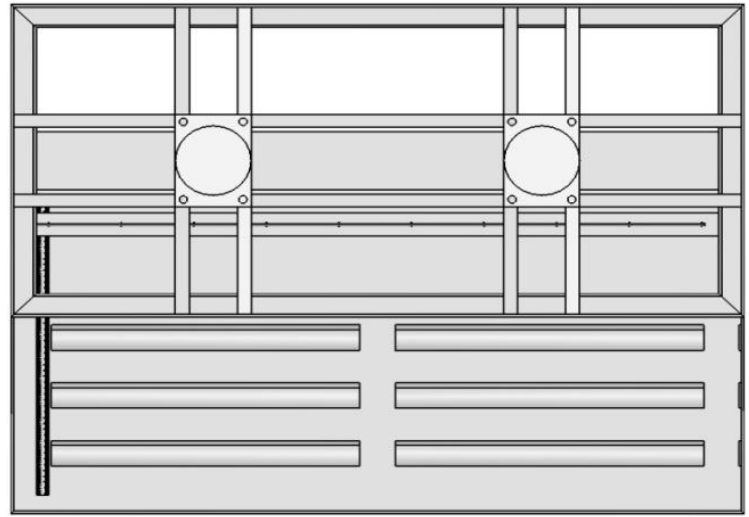

Image 5. Top View of Shearing Machine 


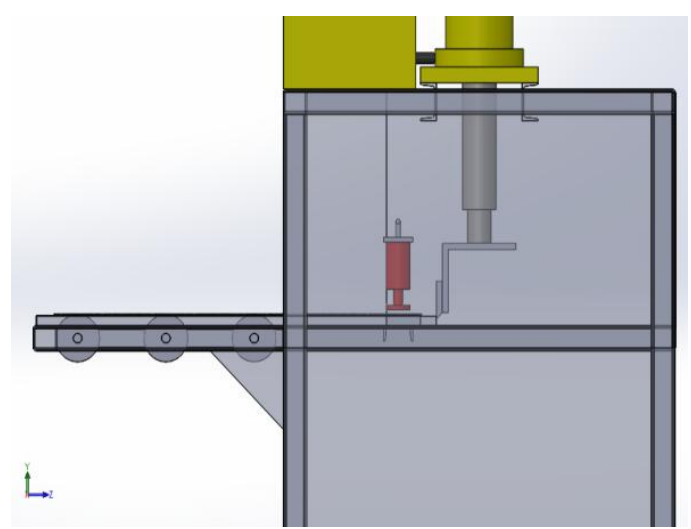

Image 6. Transparent View of Shearing Machine

\section{FE Modelling And Boundary Conditions}

A. Meshing

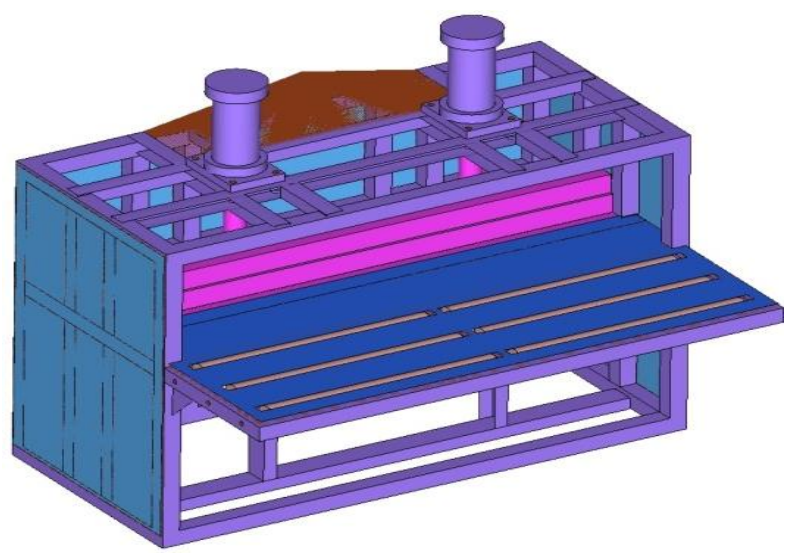

Image 7. Meshing of Shearing Machine

B. Constraints

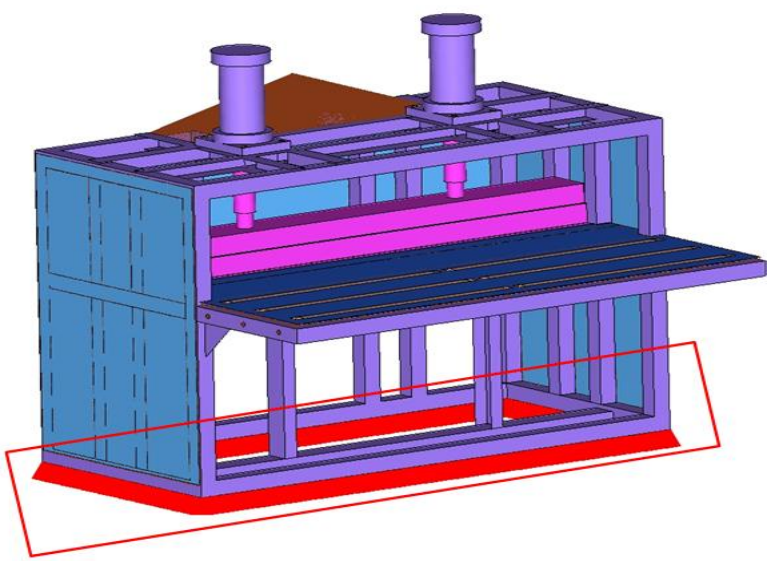

Image 8. Constraints of Shearing Machine 


\section{Forces}

Downward force at piston:

Total force $=1962 \mathrm{KN}$

No. of nodes $=344$

Load on single node $=5703 \mathrm{~N}$

Upward force at cylinder:

Total force $=1962 \mathrm{KN}$

No. of nodes $=1154$

Load on single node $=1700 \mathrm{~N}$

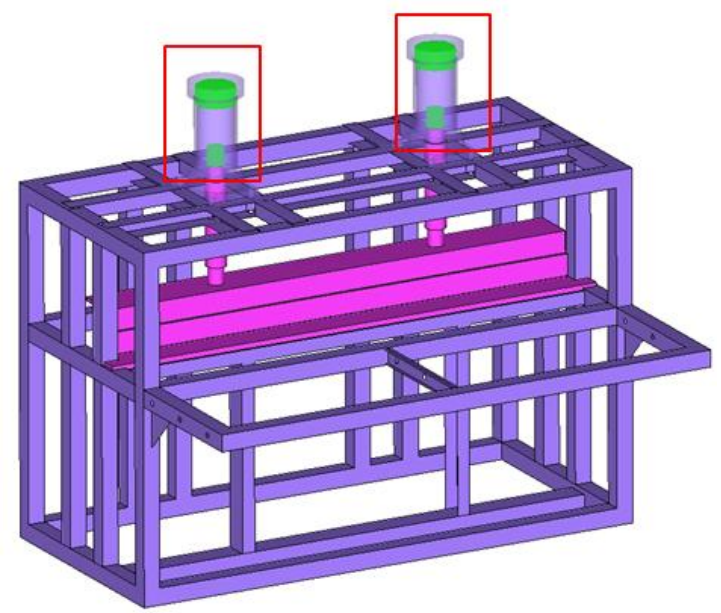

Image 9. Forces Applied on Shearing Machine

\section{Finite Element Analysis}

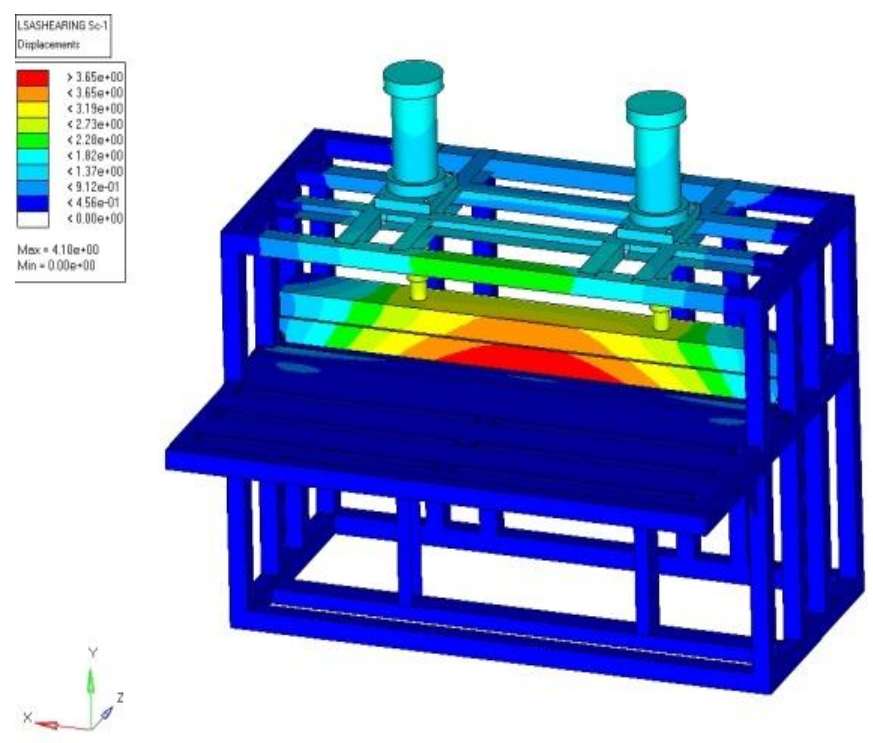

Image 10. Linear Static Analysis for Shearing Machine for Displacement DISPLACEMENT $=4.1 \mathrm{~mm}$ 


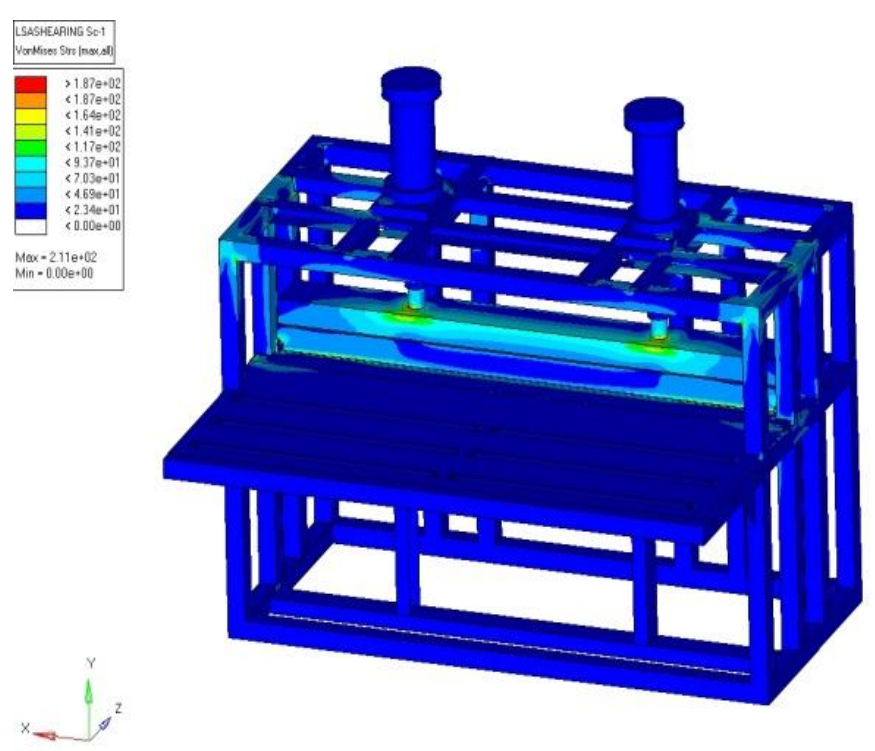

Image 11. Linear Static Analysis of Shearing Machine for VonMises Stress VonMises Stress $=211 \mathrm{MPa}$

\section{Conclusion}

In present study, we designed and developed the CAD model of shearing machine. By performing FEA analysis of and hand calculation for loads and structure design of shearing machine. With this project the company DAULAT INDUSTRIES Nagpur, will be benefited from the advancements of computer technologies and thus will be able to reduce the fabrication cost of shearing machine without compromising on the performance parameters.

\section{References}

[1] MR. SHUBHKUMAR M BHANDARI "methodology of special purpose sheet metal cutting machine".

[2] Ajit Kumar Singh, Harpreet Singh, Dharmendra Sharma, "Design and Fabrication of Pneumatic Auto Sheet Metal Cutting Machine Using Solar Energy", Dept. of Mechanical Engineering, JSSATE, Noida -201301.

[3] Bhabha Atomic Research Centre Nuclear Recycle Board Technical Specification - Shearing MachineDOCUMENT NO. IP1/102B/08067802/DOC/002/R0

[4] Date of Current Issue: 18.08.2014

[5] Emad Al-Momani, Ibrahim Rawabdehl, "An Application of Finite Element Method and Design of Experiments in the Optimization of Sheet Metal Blanking Process".

[6] Madhu Kumar V, Arun Kumar N, Harsha B S, Naveen Kumar K N, Nagaraja, "Design and Fabrication of Pneumatic Sheet Metal Cutting and Bending Machine", (IJERAT) ISSN: 24546135 [Special Volume. 02 Issue.01, May-2016]. 